Pesq. Vet. Bras. 28(10):452-456, outubro 2008

\title{
Importância de Cryptosporidium spp. como causa de diarréia em bezerros ${ }^{1}$
}

\author{
Francisco L.F. Feitosa ${ }^{2}$, Graziele M. Shimamura ${ }^{2}$, T. Roberto ${ }^{2}$, Luiz Claudio \\ N. Mendes ${ }^{2}$, Juliana R. Peiró2 ${ }^{2}$ Flávia C. Féres ${ }^{3}$, Fernanda Bovino², Silvia H.V. \\ Perri $^{2}$ e Marcelo V. Meireles ${ }^{2}$
}

\begin{abstract}
Feitosa F.L.F., Shimamura M.G., Roberto T., Mendes L.C.N., Peiró J.R., Feres F,C., Bovino, F., Perri S.H.V. \& Meireles M.V. 2008. [Importance of Cryptosporidium spp. as a cause of diarrhea in calves.] Importância de Cryptosporidium spp. como causa de diarréia em bezerros. Pesquisa Veterinária Brasileira 28(10):452-456. Curso de Medicina Veterinária, Universidade Estadual Paulista, Campus de Araçatuba, Rua Clóvis Pestana 793, Araçatuba, SP 16050-680, Brazil. E-mail: leydsonf @ fmva.unesp.br

The aim of this research was to evaluate the shedding of Cryptosporidium spp. oocysts in fecal samples from 14 calves from one dairy farm, from birth until 60 days old and from cows until eight weeks after parturition. The higher percentage of oocysts excreted was observed in 7-day-old calves. In the post-partum period $43.7 \%$ of cows were positive for Cryptosporidium oocysts. Further analyses were accomplished in 57 calves from another 32 milk farms, previously known as positive for Cryptosporidium, through oocysts fecal screening and clinical signs analyses until calves were 30 days old. Fecal samples from all animals that presented diarrhea were screened for the presence of bacteria, virus (Rotavirus and Coronavirus ) and protozoa (Eimeria spp.).
\end{abstract}

INDEX TERMS: Calves, cows, cryptosporidiosis, Cryptosporidium spp.

RESUMO.- Avaliou-se a presença de oocistos de Cryptosporidium spp. em amostras de fezes de 14 bezerros e de suas mães até a oitava semana pós parição. A maior taxa de excreção de oocistos foi verificada em bezerros com sete dias de idade. Das vacas, $42,8 \%$ foram positivas para Cryptosporidium no período pós-parto. Em outra etapa deste estudo, foram acompanhados 57 bezerros positivos para Cryptosporidium, com até 30 dias de idade, provenientes de 32 propriedades leiteiras, e estudouse o grau de eliminação dos oocistos com a possível ocorrência de diarréia. Em todos os animais positivos para Cryptosporidium foi pesquisada a presença de bactérias enteropatogênicas, vírus (Rotavirus e Coronavirus) e protozoários (Eimeria spp.).

\footnotetext{
${ }^{1}$ Recebido em 17 de março de 2008.

Aceito para publicação em 9 de abril de 2008.

${ }^{2}$ Curso de Medicina Veterinária, Faculdade de Odontologia, Universidade Estadual Paulista (Unesp), Campus de Araçatuba, Rua Clóvis Pestana 793, Araçatuba, SP 16050-680, Brasil. *Autor para correspondência: leydsonf@fmva.unesp.br

${ }^{3}$ Pós-Graduando em Ciência Animal, Curso de Medicina Veterinária, Unesp-Araçatuba, SP.
}

TERMOS DE INDEXAÇÃO: Bezerros, vacas, criptosporidiose, Cryptosporidium spp.

\section{INTRODUÇÃO}

Após sua primeira descrição por Tyzzer (1907) a criptosporidiose foi considerada, até recentemente, uma enfermidade rara e oportunista, sendo poucos os relatos de casos associados à presença de sinais clínicos.

A partir da década de 1970, Cryptosporidium spp. vem apresentando destaque crescente como agente etiológico de infecções envolvendo principalmente os sistemas digestório e respiratório de várias espécies. Somente após seu reconhecimento como agente primário de doença clínica no homem e nos animais foi que alguns tópicos relacionados a esta enfermidade, como sua epidemiologia, patogenia e características clínico-laboratoriais começaram a ser elucidados.

O envolvimento de Cryptosporidium em episódios de diarréia em bezerros neonatos foi descrito por Sanford \& Josephson (1982), que verificaram um grande número de estágios evolutivos de Cryptosporidium em enterócitos do jejuno e íleo.

Garber et al. (1994), ao examinarem amostras de fezes 
de 7.369 bezerros provenientes de 1.103 fazendas, encontraram oocistos de Cryptosporidium em 1642 animais (22,3\%) de $652(59,1 \%)$ fazendas. Quase a metade dos bezerros acometidos estava na faixa etária de sete a 21 dias, sendo a maior prevalência observada no verão.

Maldonado-Camargo et al. (1998), ao estudarem 31 fazendas leiteiras em três estados do México, observaram que o grau de infecção por oocistos de Cryptosporidium foi fortemente associado à idade dos bezerros, já que os animais com 15 dias de idade possuíam as maiores taxas de infecção.

Em bovinos, a duração dos sintomas da criptosporidiose depende de inúmeros fatores, incluindo os níveis de contaminação ambiental, a virulência e a infectividade da amostra, a suscetibilidade do hospedeiro e, por fim, a idade à primeira infecção (Lorenzo et al. 1995).

Como os sintomas desta enfermidade são inespecíficos e podem ser produzidos por outros agentes entéricos de origem infecciosa e/ou parasitária deve-se realizar diagnóstico diferencial para Escherichia coli potencialmente patogênica, salmonelose, infecções virais por Rotavirus e Coronavirus e eimeriose (Quilez et al. 2003), além de qualquer outro agente que cause diarréia em bezerros (Radostits et al. 2000).

Faubert \& Litvinski (2000) ao estudarem a transmissão natural de criptosporidiose entre vacas e seus bezerros, relataram que as vacas eliminavam maior número de oocistos no momento da parturição do que nos períodos de pré e pós-parto. A principal forma de contaminação pelo parasito é a ingestão de oocistos excretados pelas fezes de humanos ou animais; contudo, a infecção pode ser transmitida por via direta (pessoa para pessoa ou para animais), ou de forma indireta, através da ingestão de água e alimentos contaminados (Lerman et al. 1999).

O presente trabalho teve como objetivos estudar as taxas de eliminação de oocistos de Cryptosporidium em bezerros com e sem diarréia, nas primeiras semanas de vida, e em vacas em período pós-parto, bem como avaliar a importância da criptosporidiose no desenvolvimento de diarréia.

\section{MATERIAL E MÉTODOS \\ Detecção de eliminação de oocistos de Cryptospori- dium em vacas e em suas progênies}

Em uma única propriedade, sabidamente positiva para Cryptosporidium, foram colhidas amostras de fezes diretamente do reto de 14 vacas da raça Holandesa, independente da presença de diarréia, nos seguintes momentos: $24 \mathrm{~h}$ pós-parto, sete, dez, 14 e 18 dias, e na terceira, quarta, quinta, sexta, sétima e oitava semanas pós-parto, totalizando 154 amostras. Da mesma forma, foram colhidas amostras de fezes dos seus filhos nestes mesmos momentos. O regime de criação destes animais era semiintensivo, onde os bezerros permaneciam com as suas mães durante as primeiras 24 horas de vida.

\section{Determinação da participação de Cryptosporidium em episódios clínicos de diarréias em bezerros}

Em outra etapa do desenvolvimento deste estudo, foram obtidas 459 amostras de fezes de bezerros em 33 propriedades da região de Araçatuba, SP, de forma aleatória, de acordo com o número de animais que tivessem, no momento da coleta, até 30 dias de vida, independente do histórico de ocorrência de diarréia. Estes animais eram puros e/ou mestiços da raça Holandesa, sem distinção de sexo e criados em diferentes condições de manejo. As amostras de fezes, correspondentes a $\pm 30 \mathrm{~g} /$ animal, foram obtidas diretamente do reto dos bezerros por palpação digital, com a mão protegida por luva de látex, e acondicionadas em frascos coletores apropriados contendo bicromato de potássio $2,5 \%$, sendo mantidas à temperatura de $4^{\circ} \mathrm{C}$ até serem analisadas. Os animais foram divididos por faixa etária, a saber: 0-7 dias, 8-14 dias, 15-21 dias e 22-30 dias de idade. Os animais que foram diagnosticados como positivos para Cryptosporidium foram acompanhados durante os episódios diarréicos, no mínimo, uma vez por semana, até os mesmos terem cessado, para avaliação da evolução da enfermidade.

Para a detecção de oocistos de Cryptosporidium nas amostras de fezes foi utilizada a técnica de centrífugoflutuação em solução de Sheather, seguindo-se de observação em microscópio de contraste de fase. Para a determinação da quantidade de oocistos por grama de fezes, um grama de fezes foi diluído em $10 \mathrm{ml}$ de solução de Tween $20(0,1 \%)$, com contagem posterior em câmara de Neubauer.

Todas as amostras de fezes positivas para Cryptosporidium foram submetidas a diagnósticos diferenciais através de cultivo bacteriano em ágar sangue de ovino, de acordo com as recomendações de Quinn et al. (1994). Os microrganismos isolados foram identificados de acordo com suas características morfológicas e bioquímicas (Krieg \& Holt 1984). Também foram realizados exames virológicos para Rotavirus e Coronavirus, por meio de ensaio imunoenzimático (Kit-EIARA, Fundação Instituto Oswaldo Cruz, Rio de Janeiro), de acordo com Pereira et al. (1983), e coproparasitológicos para pesquisa de Eimeria spp.

Para verificar as possíveis associações entre as diferentes variáveis estudadas e as proporções comparativas das diversas categorias com relação às mesmas, foi realizado o teste de qui-quadrado ou o teste de Fisher. As estatísticas calculadas foram consideradas significativas quando $\mathrm{P}<0,05$ para contrastes entre pares de médias pelo método de Tukey. Os dados obtidos foram transformados em log $(\mathrm{x}+\mathrm{y})$ e analisados mediante o uso do programa SAS, segundo Zar (1984).

\section{RESULTADOS E DISCUSSÃO}

A avaliação dos resultados obtidos mostrou que três dos bezerros já excretavam oocistos de Cryptosporidium, juntamente com as fezes, às 24 horas de vida (Quadro 1), o que representa um forte indício de que os animais são rapidamente infectados logo após o nascimento. A transmissão de oocistos ocorreu, provavelmente, pelo ato da amamentação, em virtude da permanência dos neonatos com as suas mães (contato da boca com tetas contami- 


\begin{tabular}{|c|c|c|c|c|}
\hline Período & $\begin{array}{c}\text { № de animais } \\
\text { positivos } \\
\text { Bezerros / Mães }\end{array}$ & $\begin{array}{l}\text { Porcentagem } \\
\text { Bezerros / Mães }\end{array}$ & $\begin{array}{c}\text { № de animais } \\
\text { negativos } \\
\text { Bezerros / Mães }\end{array}$ & $\begin{array}{l}\text { Porcentagem } \\
\text { Bezerros / Mães }\end{array}$ \\
\hline 24 horas & $3 / 1$ & $21,5 / 7,1$ & $11 / 13$ & $78,5 / 92,9$ \\
\hline $7^{\circ}$ dia & $11 / 2$ & $78,5 / 14,2$ & $3 / 12$ & $21,5 / 85$ \\
\hline $15^{\circ} \mathrm{dia}$ & $3 / 0$ & $21,5 / 0$ & $11 / 14$ & $78,5 / 100$ \\
\hline $18^{\circ} \mathrm{dia}$ & $1 / 2$ & $7,1 / 4,2$ & $13 / 12$ & $92,9 / 85$ \\
\hline $3^{\mathrm{a}}$ a $8^{\mathrm{a}}$ semanas & $0 / 3$ & $0 / 21,5$ & $14 / 11$ & $100 / 78,5$ \\
\hline
\end{tabular}

nadas) ou pela provável contaminação do ambiente em que os bezerros permaneciam durante os primeiros dias de vida, uma vez que os oocistos eliminados no meio ambiente apresentam grande resistência às diferentes condições ambientais. Como o período pré-patente é maior que 24 h, é possível que esses oocistos tenham sido ingeridos e eliminados de forma passiva, sem ocorrência de excitação, como já observado em anfíbios, aves, peixes e répteis (Graczyk et al. 1996, 1996a, 1997). Contudo, estes animais continuavam positivos na coleta realizada no $7^{\circ}$ dia de vida, confirmando a importância da contaminação ambiental.

A excreção de oocistos de Cryptosporidium em fezes ocorreu até o $18^{\circ}$ dia de idade. Entretanto, a faixa etária que mais apresentou amostras positivas para oocistos (Quadro 1) foi a de animais com sete dias de idade (11 dos 14 bezerros, 72,7\%), contrariando, em parte, os resultados observados por outros pesquisadores, tais como Garber et al. (1994), que afirmaram ser o $12^{\circ}$ dia o período mais adequado para se encontrar oocistos em fezes de bezerros, e Maldonado-Camargo et al. (1998), que encontraram maiores taxas de excreção em animais com 15 dias de idade.

Como observado no Quadro 1, o sétimo dia de vida foi o momento em que houve maior número de bezerros positivos para Cryptosporidium. Todos os animais positivos, às $24 \mathrm{~h}$ de vida, eliminavam oocistos no $7^{\circ}$ dia de idade, sendo que somente um animal positivo, neste período, continuava eliminando oocistos aos $15^{\circ}$ e $18^{\circ}$ dias de coleta.

A participação de animais adultos parece ser de grande importância na contaminação do ambiente e disseminação da criptosporidiose, como mencionado por Faubert \& Litvinsky (2000), pois 6 das 14 vacas estudadas $(42,8 \%)$ apresentavam-se positivas no período pós-parto. Como demonstrado no Quadro 1, uma das mães continuava eliminando oocistos de Cryptosporidium em dois momentos de coleta, aos $7^{\circ}$ e $18^{\circ}$ dias pós-parto (DPP), respectivamente. Outro animal em que a primeira eliminação foi ao $18^{\circ}$ DPP teve recidiva na $5^{a}$ semana pós-parto (SPP). Mesmo assintomáticos, não se deve negligenciar o potencial desses animais como portadores de oocistos de Cryptosporidium, já que são importantes fontes de contaminação para os bezerros. Essa porcentagem, contudo, é menor do que o reportado por Lorenzo et al. (1993), que encontraram $71,75 \%$ de animais adultos positivos para Cryptosporidium.

Pouquíssimos são os trabalhos nacionais que estudaram a ocorrência da diarréia em animais recém-nascidos. Contudo, nenhum problema é mais comum na criação de bezerros do que as enterites infecciosas. A correlação entre os níveis de infecção por Cryptosporidium com a freqüência e a intensidade do principal sintoma, a diarréia, foi avaliada utilizando-se 57 amostras de bezerros positivos para este parasito. De 57 animais, 15 apresentavam ou desenvolveram diarréia durante o acompanhamento clínico (Quadro 2), enquanto que 42 animais eram portadores assintomáticos, taxa semelhante à observada por Ortolani (1988) e próxima a encontrada por Ribeiro et al. (2000) em bezerros bubalinos, que encontraram infecção por Cryptosporidium em 8,3\% (4/48) dos animais com diarréia.

Observou-se, em $65 \%$ das amostras positivas para Cryptosporidium (37/57), isolamento de Escherichia coli, sendo que mais de um agente etiológico encontrava-se envolvido em várias delas (E. coli, Salmonella sp., Shigella sp. e Proteus sp.). Detectou-se, concomitantemente, crescimento bacteriano em 100\% (15/15) das amostras diarréicas positivas para Cryptosporidium. No diagnóstico diferencial, 11 animais foram positivos para $E$. coli, dois destes em associação com Proteus sp. ou Eimeria, e outros três mostraram-se positivos para Salmonella. Apenas duas amostras de fezes diarréicas foram positivas para Rotavirus, microrganismo tradicionalmente apontado como um dos mais prevalentes causadores da diarréia, o que contraria os achados de Buzinaro et al. (2003), que detectaram um grande número de bezerros com ida-

Quadro 2. Número e porcentagem de amostras de fezes positivas para oocistos de Cryptosporidium, diarréicas e não diarréicas, de acordo com a faixa etária. Araçatuba, 2006

\begin{tabular}{|c|c|c|c|c|c|c|}
\hline \multirow{3}{*}{$\begin{array}{c}\text { Faixa etária } \\
\text { (dias) }\end{array}$} & \multirow{2}{*}{\multicolumn{2}{|c|}{$\begin{array}{c}\text { Presença de oocistos } \\
\text { nas fezes }\end{array}$}} & \multicolumn{2}{|c|}{ Sem diarréia } & \multicolumn{2}{|c|}{ Com diarréia } \\
\hline & & & \multirow[t]{2}{*}{ № } & \multirow[t]{2}{*}{$\%$} & \multirow[t]{2}{*}{ № } & \multirow[t]{2}{*}{$\%$} \\
\hline & № & $\%$ & & & & \\
\hline 0 a $7(n=150)$ & 22 & 14,7 & 20 & 47,6 & 2 & 13,3 \\
\hline 8 a $14(n=165)$ & 24 & 14,5 & 15 & 35,7 & 9 & 60,1 \\
\hline 15 a $21(n=59)$ & 5 & 8,4 & 3 & 7,1 & 2 & 13,3 \\
\hline 22 a $30(n=85)$ & 6 & 7,0 & 4 & 9,5 & 2 & 13,3 \\
\hline Total $(n=459)$ & 57 & 12,4 & 42 & 100 & 15 & 100 \\
\hline
\end{tabular}




\begin{tabular}{|c|c|c|c|c|}
\hline Faixa etária & $\begin{array}{l}\text { Sem diarréia } \\
\text { (dias) } \bar{X} \pm S\end{array}$ & $\begin{array}{c}\text { Com diarréia } \\
\bar{X} \pm S\end{array}$ & $\begin{array}{c}\text { Sem diarréia } \\
\text { Min - Max }\end{array}$ & $\begin{array}{c}\text { Com diarréia } \\
\text { Min - Max }\end{array}$ \\
\hline 0 a $7(n=22)$ & $2789,94 \pm 6219,03$ & $2170,56 \pm 1172,16$ & $78,13-24166,67$ & $1044,52-4484,53$ \\
\hline 8 a $14(n=24)$ & $4836,24 \pm 9314,28$ & $6392,43 \pm 1429,04$ & $637,00-40381,46$ & $5381,94-7402,91$ \\
\hline 15 a $21(n=5)$ & $2323,68 \pm 1946,00$ & $2440,84 \pm 3272,39$ & $520,83-5147,05$ & $595,23-7343,75$ \\
\hline 22 a $30(n=6)$ & $1180,18 \pm 1197,62$ & * & $333,33-2027,02$ & * \\
\hline
\end{tabular}

* Apenas um animal apresentou diarréia na referida faixa etária.

des variando entre 30 e 60 dias com amostras fecais positivas para o referido agente etiológico. Em nenhuma amostra de fezes foi constatada a presença de Coronavirus. Ribeiro et al (2000) mencionaram a presença de outros enteropatógenos bacterianos nas fezes de bezerros bubalinos, demonstrando a etiologia multifatorial das enterites em ruminantes.

A maioria dos animais que desenvolveu diarréia (60\%) tinha entre sete e 14 dias de vida. De forma semelhante ao relato de Pohjola et al. (1986), a maior parte dos animais com diarréia e positivos para criptosporidiose encontrava-se na faixa etária compreendida entre a primeira e a segunda semanas de vida $(47,6 \%)$. A constatação de que bezerros com até 14 dias de idade apresentavam diarréia com maior freqüência do que animais mais velhos concilia-se com as verificações de Reynols et al. (1986) e Ortolani (1988), que sugeriram que os animais nesta faixa etária possuíam grande probabilidade de apresentar enterite de origem infecciosa quando comparados com animais mais velhos. Contudo, deve-se ressaltar que cerca de $74,0 \%$ dos bezerros (42/57) que excretavam oocistos de Cryptosporidium e encontravamse na faixa etária compreendida entre a primeira e segunda semanas de vida eram assintomáticos (Quadro 2), demonstrando, com isso, sua importância como fonte primária de contaminação ambiental e de infecção criptosporídica. Tais achados servem como alerta aos colegas e criadores no que tange à adoção de práticas de manejo que visem o aprimoramento da prevenção da infecção por Cryptosporidium spp. Esses dados são semelhantes aos descritos por Souza \& Lopes (1995), que observaram $64,7 \%$ de positividade em 51 bezerros assintomáticos.

Observou-se enorme variação no número de oocistos/ $\mathrm{g}$ de fezes em animais assintomáticos quando comparados aos animais que apresentavam diarréia, principalmente naqueles com até sete dias de vida (Quadro 3). As maiores taxas de eliminação foram observadas em animais com idades variando entre oito e 14 dias e com quadro diarréico. Não foi possível observar diferenças estatísticas com relação ao número de oocistos excretados por animais assintomáticos e animais diarréicos, em virtude da grande variação dos valores de desvio-padrão obtidos. No entanto, os resultados deste trabalho demonstraram que Cryptosporidium é um importante agente etio- lógico de diarréia em animais com até 15 dias de idade, como descrito anteriormente por Naciri et al. (1999).

Foi observada, durante o período de convalescença, em 19,3\% (11/57) dos bezerros, discreta desidratação (Quadro 4), sendo que somente três bezerros apresentavam-se com desidratação moderada. A grande maioria não apresentava qualquer alteração clínica sugestiva de desequilíbrio hídrico-eletrolítico relevante. À avaliação física geral dos bezerros constatou-se nível de consciência inalterada e temperatura retal dentro dos valores considerados normais. Nos bezerros com desidratação não foi necessário, no momento da avaliação e do diagnóstico, suporte hídrico ou eletrolítico para o seu restabelecimento, já que todos mantiveram inalterados o reflexo de sucção e o apetite. Não se fez necessária a administração de antibióticos, pois apresentavam, durante o acompanhamento clínico, evolução satisfatória. Contudo, há geralmente, na fase do quadro diarréico, uso abusivo e indiscriminado de antibióticos por parte dos criadores, por pensarem se tratar de diarréia bacteriana, o que ocasiona grande prejuízo econômico e, também, desenvolvimento de resistência bacteriana aos antibióticos utilizados.

A maioria das fezes dos bezerros deste experimento apresentava-se com consistência semilíquida a líquida (Quadro 5), de coloração amarela ou branco-esverdeada, sem alteração marcante em seu odor. Alguns animais apresentavam presença de sangue nas fezes (hematoquezia) e tenesmo.

Quadro 4. Distribuição de 57 bezerros positivos (em número e porcentagem) para criptosporidiose, de acordo com o grau de desidratação (Naciri et al. 1999)

\begin{tabular}{|c|c|c|c|c|}
\hline Scores & Classificação & Desidratação & $\begin{array}{c}\text { № } \\
\text { Animais }\end{array}$ & $\begin{array}{c}\% \\
\text { Animais }\end{array}$ \\
\hline Grau 0 & Normal & $\begin{array}{l}\text { Elasticidade da pele normal } \\
\text { Ausência de enoftalmia } \\
\text { Mucosas úmidas }\end{array}$ & 43 & $75,4 \%$ \\
\hline Grau 1 & Leve & $\begin{array}{c}\text { Perda de Elasticidade }<5 s \\
\text { Ausência de enoftalmia } \\
\text { Mucosas úmidas }\end{array}$ & 11 & $19,3 \%$ \\
\hline Grau 2 & Moderada & $\begin{array}{l}\text { Perda de Elasticidade }>5-30 \text { s } \\
\text { Enoftalmia leve a moderada } \\
\text { Mucosas levemente secas }\end{array}$ & 3 & $5,3 \%$ \\
\hline Grau 3 & Severa & $\begin{array}{c}\text { Perda de Elasticidade }>30 \text { s } \\
\text { Enoftalmia severa } \\
\text { Mucosas secas }\end{array}$ & 0 & $0 \%$ \\
\hline
\end{tabular}


Quadro 5. Distribuição de 57 bezerros positivos (em
número e porcentagem) para Cryptosporidium, de acordo
com o grau de consistência das fezes (Naciri et al. 1999)

\begin{tabular}{lccc}
\hline Scores & Parâmetros & № Animais & \%Animais \\
\hline Grau 0 & Ausência de diarréia & 43 & $75,4 \%$ \\
Grau 1 & Fezes pastosas & 1 & $1,8 \%$ \\
Grau 2 & Fezes semi-líquidas & 9 & $15,8 \%$ \\
Grau 3 & Fezes líquidas & 4 & $7,0 \%$
\end{tabular}

As constatações de Tzipori et al. (1983) de que Cryptosporidium é um agente determinante primário no desenvolvimento da diarréia, ressaltam, sem sombra de dúvida, a sua importância, juntamente com os demais agentes bacterianos e virais, no complexo etiológico das diarréias de bezerros neonatos no nosso país. Supõe-se, contudo, que $50 \%$ dos casos de diarréia são devidos a $E$. coli (Tello et al. 1990). Entretanto, é possível que vários fatores como bactérias enteropatogênicas, protozoários e vírus, além das características ambientais e a capacidade imune possam interagir no desencadeamento de enterites em bezerros, sem que haja, na grande maioria dos casos, uma simples e única etiologia envolvida.

Agradecimentos.- Os autores agradecem o aporte financeiro deferido pela FAPESP para a realização desse trabalho (Proc.99/03626-9).

\section{REFERÊNCIAS}

Buzinaro M.G., Mistieri M.L.A., Carvalho A.A.S., Samara S.L., Regitano L.C. \& Jerez J.A. 2003. Prevalência de rotavírus do grupo A em fezes diarréicas de bezerros de corte em sistema semi-intensivo de produção. Arq. Bras. Med. Vet. Zootec. 55:266-270.

Faubert G.M. \& Litvinsky Y. 2000. Natural transmission of Cryptosporidium spp. between dams and calves on dairy farm. J. Parasitol. 86:495500.

Garber L.P., Salman M.D., Hurd H.S., Keefe T. \& Schalater J.L. 1994. Potential risk factor for Cryptosporidium infections in dairy calves. J. Am. Vet. Med. Assoc. 205:86-91.

Graczyk T.K., Cranfield M.R., Fayer R. \& Anderson M.S. 1996. Viability and infectivity of Cryptosporidium parvum oocysts are retained upon intestinal passage through a refractory avian host. Appl. Environ. Microbiol. 62:3234-3237.

Graczyk T.K., Fayer R. \& Cranfield M.R. 1996a. Cryptosporidium parvum is not transmissible to fish, amphibians, or reptiles. J. Parasitol. 82:748751.

Graczyk T.K., Cranfield M.R., Fayer R., Trout J. \& Goodale J.H. 1997. Infectivity of Cryptosporidium parvum oocysts is retained upon intestinal passage through a migratory water-fowl species Canada goose (Branta canadensis). Trop. Med. Int. Health 2:341-347.

Krieg N.R. \& Holt J.G. 1984. Bergey's Manual of Systematic Bacteriology. Williams and Wilkins, London. 984 p.

Lerman de Abramovich B., Lura M.C., Gilli M.I. \& Haije M.A. 1999. Cryptosporidium and water. Revta Argent. Microbiol. 31:97-105.
Lorenzo M.J., Ares-Mazas E. \& Villacorta M.M. 1993. Detection of oocysts and IgG antibodies to Cryptosporidium spp. in asymptomatic adult cattle. Vet. Parasitol. 47:9-15.

Lorenzo M.J., Ben B., Mendez F., Villacorta I. \& Ares-Mazar M.E. 1995. Cryptosporidium spp. oocyst antigens recognized by sera from infected asymptomatic adult cattle. Vet. Parasitol. 60:17-25.

Maldonado-Camargo S., Atwill E.R., Saltijeral-Oaxaca J.A. \& HerreraAlonso L.C. 1998. Prevalence of and risk factors for shedding of Cryptosporidium spp. in Holstein-Friesian dairy calves in central Mexico. Prev. Vet. Med. 36:95-107.

Naciri M., Lefay M.P., Mancassola R., Pairier P. \& Chemette R. 1999. Role of Cryptosporidium spp. as a pathogen in neonatal diarrhea complex in suckling and dairy calves in France. Vet. Parasitol. 85:245257.

Ortolani E.L. 1988. Padronização da técnica de Ziehl-Neelsen para pesquisa de oocistos de Cryptosporidium: estudo de alguns aspectos epidemiológicos de criptosporidiose em bezerros de rebanhos leiteiros no Estado de São Paulo. Tese de Doutorado, Instituto de Ciências Biomédicas, Universidade de São Paulo (USP), São Paulo.

Pereira H.G., Azevedo R.S. \& Leite J.P.G. 1983. Electroforetic study on the genome human rotaviruses from Rio de Janeiro, São Paulo and Paraná, Brazil. J. Hyg. 90:117-1126.

Pohjola S.S., Oksanen H., Neuvonem E., Veijalainen P. \& Henriksson K. 1986. Certain enteropathogens in calves of finish dairy herds with recurrent outbreaks of diarrhea. Prev. Vet. Med. 3:547-558.

Quilez J., Acedo C.S. \& Cacho E. 2003. Criptosporidioses de los pequenos ruminantes. Peq. Rum. 4(2):1-20.

Quinn P.J., Carter M.E., Markley B.G. \& Corta G.R. 1994 Clinical Veterinary Microbiology. Wolfe, London. 654p.

Radostits O.M., Gay C.C., Blood D.C. \& Hinchcliff K.W. 2000. Veterinary Medicine: A textbook of the diseases of cattle, sheep, pigs, goats and horses. 9th ed. Baillière Tindall, London. 1502p.

Reynolds D.J., Morgan J.H., Chanter N., Jones P.W., Bridger J.C., Debney T.G. \& Bunch K.J. 1986. Microbiology of calf diarrhoea in southern Britain. Vet. Rec. 119:34-39.

Ribeiro M.G., Langoni H., Jerez J.A., Leite D.S., Ferreira F. \& Gennari S.M. 2000. Identification of enteropathogens from buffalo calves with and without diarrhoea in the Ribeira Valley, State of São Paulo, Brazil. Braz. J. Vet. Res. Anim. Sci. 37:34-39.

Sanford S.A. \& Josephson G.K.A. 1982. Bovine cryptosporidiosis: clinical and pathological findings in forty-two scouring neonatal calves. Can. Vet. J. 23:343-347.

Souza J.C.P. \& Lopes C.W.G. 1995. Criptosporidiose em bezerros da Bacia Leiteira do Sul Fluminense, Estado do Rio de Janeiro. Revta Bras. Parasitol. Vet. 4(1):33-36.

Tello S.G., Sumano Lopes H. \& Caballero Chacón S.C. 1990. Fisiología y farmacología clínica de las diarreas en becerros. Vet. Mex. 21:285308.

Tzipori S., Smith M., Halpin C., Angus K.W., Scherwood D. \& Campbell I. 1983. Experimental cryptosporidiosis in calves: clinical manifestation and pathological findings. Vet. Rec. 112:116-120.

Tyzzer E.E. 1907. A sporozoan found in the peptic glands of the common mouse. Proc. Soc. Exp. Biol. Med. 5:12-13.

Zar J.H. 1984. Biostatistical Analysis. $2^{\text {nd }}$ ed. Prentice-Hall, Englewood. $718 p$. 